\title{
Rural Areas Interoperability Framework: Intelligent Assessment of Renewable Energy Security Issues in PAKISTAN
}

\author{
Shahid Naseem**, Muhammad Irfan Abid**, Muhammad Kamran**, Muhammad Rayyan Fazal**, \\ Ghulam Abbas***, Muhammad Rizwan Abid****, Zunair Zamir** \\ *Division of Science and Technology, University of Education, Lahore, Pakistan \\ **Department of Electrical Engineering and Technology, Riphah International University, Faisalabad, Pakistan \\ ***Electrical Engineering Department, University of Lahore, 54000, Pakistan \\ ****Department of Computer Science, Florida Polytechnic University (FPU), Lakeland, Florida, USA \\ (shahid.naseem@ue.edu.pk,mirfanabid@riphahfsd.edu.pk,kamran_ramzan@outlook.com,rayyan.m@yahoo.com)
}

¥Corresponding Author, Shahid Naseem, Tel: +92 300 5305627, shahid.naseem@ue.edu.pk

Received: xx.xx.xxxx Accepted:xx.xx.xxxx

\begin{abstract}
Electricity is an important component of our life. It plays an important role in social development as it improves people's living standards in urban as well as in rural areas of Pakistan. According to the International Energy Agency (IEA), till 2017, 45\% of Pakistani were living without electricity in rural areas. In Pakistan, load shedding remains a critical issue due to hectic energy threats, which are alarming for development especially in rural areas. Currently, there are 10 hours of load shading in cities and 12 to 14 hours in rural areas. There is a need to implement innovative, less costly tools and materials that can convert fossil fuels into renewable energy resources to generate electricity to overcome the load shedding problems in Pakistan, especially in rural areas. To overcome the load-shedding problems and to convert the fossil fuels into renewable energy successfully, we have proposed a Rural Areas Interoperability (RAI) framework for analyzing the geographical and environmental situations, feudal system in Sindh, Balochistan, KPK and some areas in Punjab. Moreover, we have suggested a suitable renewable energy resource out of existing renewable energy resources i.e. solar system, wind energy, hydro energy, biomass biogas and thermal energy in a particular area to generate the electricity after analyzing the security issues for installation of these renewable energy resources in the specific area of a district in Pakistan.
\end{abstract}

Keywords: load shedding, hydro, renewable, rural, fossil fuels

\section{Introduction}

Pakistan is blessed with plenty of renewable energy generation resources but these resources are only used in hydropower projects for generating electricity to fulfill the electricity demand in the urban as well as rural areas of Pakistan. Pakistan is one of these countries in the world, where the demand for electricity reaches a critical stage due to a shortage of water in the rivers flowing in Pakistan. That is why in Pakistan the duration of load shedding in urban areas reached 10 to 12 hours whereas in rural areas it reaches 14 to 16 hours in the peak hours [1].

Pakistan is expected to continue being affected by electricity load shedding until the last month of the year at least because the existing transmission and distribution network cannot carry more than 19,500 MW against a peak demand of over, 23,837 MW. Being a developing country, Pakistan is importing oil from different Middle East countries to produce electricity to fulfill the electricity demands in the rural as well as urban areas. As the population of Pakistan is increasing day by day and its fossil fuels are also increasing continuously, Therefore, there is a need for some sources that can convert these fossil fuels into electricity to minimize the import of oil from other counties [2].

Pakistan is facing a formidable challenge of energy shortage with the demand outweighing its supply. The energy shortage has adversely affected all sectors of the economy resulting in an annual loss of up to $3 \%$ of GDP. Disproportionate reliance on imported oil i.e. $85 \%$ of the 
total supply is exerting a strain on the balance of payments. The existing energy mix components in Pakistan are [3]:

Table 1: Existing Energy Mix Components in Pakistan

\begin{tabular}{|c|c|}
\hline Component & Percentage \\
\hline Gas & $48 \%$ \\
\hline Oil & $33 \%$ \\
\hline Hydel & $11 \%$ \\
\hline Coal & $6 \%$ \\
\hline Nuclear & $2 \%$ \\
\hline
\end{tabular}

Many Asian counties including India, Bangladesh, Bhutan, China, Afghanistan, Japan have made major advancements to increase its renewable energy in its overall energy potential to overcome the energy shortage. The number of peoples in million is living without electricity in different countries in the world as shown in fig 1.

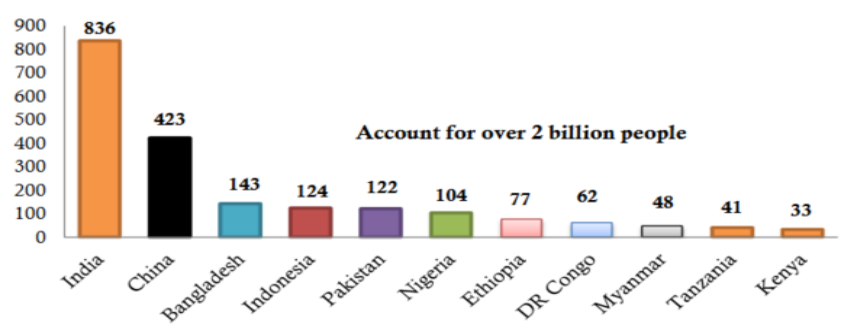

Fig 1: Highest population without access to electricity country-wise

Like other Asian counties, in recent years, in Pakistan, various efforts have been made to utilize renewable energy resources but this contribution is low as compared to other Asian countries. Instead, Pakistan is fulfilling its energy requirements through oil and gas, which is enough to fulfill our $70 \%$ electricity requirements. The production is electricity is insufficient that is why load shedding is being observed in every district of the country [4]. The detail of energy potential generation in Asian countries is shown in Table 2.

The Government of Pakistan can use different renewable energy resources to produce energy to overcome the load shedding issues in the country. A systematic study based on successful experiences regarding the use of renewable energy systems in Ecuador is presented [5]. This step of the Government leads the investors to invest in Pakistan for establishing renewable energy resources in remote areas to facilitate the people living in these areas. Also, we have to understand that utilities around the world are facing severe competition because of the cheap renewable energy prices. A dynamic tariff strategy may be helpful to cater to this problem [6]. Distribution networks have to deal with the embedded generation issue, hence to design a power system the impact of renewable energy resources in the Power grid must keep in mind [7, 8]. The existing renewable energy resources $(\mathrm{KW} / \mathrm{h})$ and energy generation capacity $(\mathrm{KW} / \mathrm{h})$ in Pakistan are shown in table 3:

Table 3: Renewable Energy Resources in Pakistan

\begin{tabular}{|c|c|c|}
\hline $\begin{array}{c}\text { Renewable } \\
\text { Resources }\end{array}$ & $\begin{array}{c}\text { Electricity } \\
\text { Generation } \\
\text { Potential (KW/h) }\end{array}$ & $\begin{array}{c}\text { Renewable } \\
\text { Electricity } \\
\text { Generation }\end{array}$ \\
\hline Wind Energy & 49,760 & $1,227 \%$ \\
\hline Solar Energy & 399,810 & $9,862 \%$ \\
\hline Biogas Energy & 488 & $12 \%$ \\
\hline $\begin{array}{c}\text { Thermal } \\
\text { Energy }\end{array}$ & 31,653 & $781 \%$ \\
\hline Hydel Energy & 536 & $13 \%$ \\
\hline
\end{tabular}

Increasing industrialization and expansion have raised the demand for electricity in the country for the last few years. Thus, Pakistan must take the initiative to introduce renewable energy resources in the country that have not yet been processed in a meaningful way. It is estimated that if the energy is generated more, the country's progress will be maximum.

\subsection{Renewable Energy Security Issues}

In the country, increasing the fossil fuels, the difference between demand and supply of electricity, increasing the national and international debts, lack of technologies are the big security threats for economic growth and the development as well as its environmental impact is also alarming to the Government of Pakistan. These security threats are a big challenge to the Government, experts, and technologists to convert fossil fuels into renewable energy resources to generate electricity to overcome the load shedding problems in the country. This situation leads the experts to use some new techniques that can utilize renewable resources more efficiently to produce more outcomes than existing techniques to fulfill the energy requirements in the urban as well as in the rural areas of Pakistan. According to the IEA report 2017, there are still 40,000 villages in Pakistan that are without electricity and gas [9]. Its main reason is that several vehicles using $\mathrm{CNG}$ rather than fuel at $\mathrm{CNG}$ stations are considered the main reason for the on-going energy crisis.

There are many problems in introducing renewable energy in such remote areas, but nothing too tough to handle. Renewable energy applications for both on-grid and off-grid have also many challenges. The government has to set an integrated policy to install any renewable energy resources such as Wind, Solar, Thermal or Hydropower plant, etc. There are also some other security issues in private, public as well as in financial sectors $[10,11]$.

In rural areas, electricity is not only be used for lighting, heating and cooking, drinking water, agriculture for crop processing, small industries, refrigeration, and motive-power purposes. There is very limited information available on both the demand and supply of electricity in rural areas. This limited information about the energy demand; availability of foreign investors, suitable technology is required to the 
assessment of people living in the rural off-grid areas and to take initiative to serve in these areas.

Table 2: Energy Potential Generation Country-wise

\begin{tabular}{|c|c|c|c|c|c|c|}
\hline Country & Hydro & Wind & Biomass & Solar & Thermal & $\begin{array}{c}\text { Percentage } \\
\text { generation (\%) }\end{array}$ \\
\hline Afghanistan & 710 & - & - & - & - & $80.32 \%$ \\
\hline Bangladesh & 1,830 & - & - & - & - & $8.31 \%$ \\
\hline Bhutan & 6,745 & - & - & - & - & $99.99 \%$ \\
\hline China & $1,130,270$ & 185,766 & 52,700 & 45,225 & 125 & $24.32 \%$ \\
\hline India & 138,052 & 42,790 & 24,892 & 5,636 & - & $19.11 \%$ \\
\hline Japan & 86,942 & 5,038 & 35,253 & 24,506 & 2,577 & $15.51 \%$ \\
\hline Pakistan & 29,558 & 256 & - & 1,000 & - & $31.85 \%$ \\
\hline
\end{tabular}

The people living in remote areas of Pakistan are unaware, how they solve their energy-related problems, from whom they must contact to raise their electricity issues. The other problems are the lack of operational and maintenance experts or technicians, expertise in risk assessment of renewable energy resources because the people living in these areas are living sub-standard lives and below the poverty, baseline to pay their electricity bills.

Thermal power is caused by the high cost of electricity in Pakistan. The influence of thermal power in the total energy potential of the country is $2 / 3$. The interest of International and National Lobbies for the promotion of thermal power in Pakistan is caused to raise the cost of electricity in the country, inflation and unreliability of the National Grids, etc. The other cause to raise the electricity cost in the country is the IPP's $38.6 \%$ contribution to the total energy potential of the country but the overall energy potential assessment is appreciation in fuel price deduction and delays in the payments are caused by circular debt in the country [12].

Improper NEPRA tariff for domestic and commercial utilization of electricity in the country, line losses of electricity, departmental corruption as well as line-men corruption, dispute on the tariff in different districts of the country are responsible for proliferation the per-unit rate of electricity. Delay in the electricity payments to the other countries, lack of investments from foreign investors, delay in loan from local banks and lack of technologies and expertise and the pressure of IMF to increase the electricity rate in the country are the main caused to high rate of electricity which leads the country to take an initiate to the renewable energy resources. Presently, Pakistan's per capita income is approximately $\$ 1258$ and its electricity cost is already very high due to the increase in thermal power generation.

\subsubsection{Management Issues}

Poor management of renewable energy resources in the country is due to the political influences which can cause to increase its circular debts. The procedure of installation of rental power plants in Pakistan depicts the political influence on the Government. It can also cause to appointments without merits, appointments of un-eligible and nontechnical persons. Some of the other management issues are as follow [13]: a) Aligning economic enticements through policies, regulations, subventions, tariffs, collections of taxes to improve economics discipline and transparency, attract investment and encourage energy conservation and efficiency improvements.

b) Creating sufficient capacity to authorize investors such as the Government of Pakistan, the private sector, NGOs and energy consumers to both implement and respond to the enticements frameworks.

c) Dependence of rural households on firewood, rising costs of fossil fuels, air pollution and climate changes are the main challenges that must be addressed by classifying the power production fuel inputs and adopting renewable energy technologies.

d) Provides electricity to villages with renewable energy resources is a unique challenge for an organization to maintain and own the systems while promoting the private sector for development.

e) Privatization/efficiency

f) Energy Demands

g) Economic growth for energy

h) Electricity for remote areas.

i) Energy policy for remote areas.

j) Renewable energy resources instead of conventional energy resources

\subsubsection{Energy Security and Regional Situation}

The energy sector of Pakistan has relied on oil, which can cause some international conflicts for routes to import oil in Pakistan from other countries such as Russia and Qatar etc. Further, if there is an unstable situation in the country as well as blockage of seaports, it can cause to stop the production of electricity from thermal plants. The aboriginal of oil and gas reserves in the country is expected to exhaust in 13 to 16 years respectively. Pakistan tries to negotiate with other oil-producing countries to import oil from these countries to fulfill its energy needs. For this purpose, Pakistan has signed MOU with Iran, Kirghizstan and Tajikistan to import 10,000 MW electricity as well as with Qatar to import gas [14]. But due to the instability of 
Afghanistan, security issues in Sindh and Baluchistan has reduced the planned routes.

Pakistan has 27.5 Trillion cubic feet recoverable gas reserves and producing $32 \%$ of its electricity from natural gas. Pakistan's per day gas production is around 4 Billion Cubic Feet, whereas the demand is approximately 6 Billion Cubic Feet per day. The gas production demand will increase 8 Billion Cubic Feet per day by 2025 but it is expected to fall to less than 1 BCFD as a result of the reduction of gas reserves. Nearly $1 / 3$ of the indigenous natural gas is used for the generation of electricity which is causing a severe industrial and domestic gas load shedding. This is causing significant damage to the country's export earnings which increased the import bill. Given the prevailing energy crises and exponentially decreasing gas reserves, importing gas from neighboring gas-rich countries has become the need of the hour. TAPI gas pipeline project is required to increase its pace to meet the energy requirements of Pakistan in different regions as compared to IPI [15].

\section{Background Literature}

The empowerment of the Renewable Energy sector in Pakistan is need of the hour, SWOT analysis is performed in this regard [16]. The per-year solar potential of Pakistan is approximately $2,990 \mathrm{MW}$ that is composed of 58 meteorological stations' climatic data collected using Angstrom and Hargreaves's formulas. Pakistan is an important place for the manipulation of solar energy from sunlight. According to him, in most parts of the country, about 8 to 10 hours of sun rays can be achieved for producing solar energy [17]. A simple adaptive system based on Photovoltaic systems can be helpful in energy storage during dynamic climatic conditions. It can also be helpful to forecast the energy consumption of households with the help of the same system [18].

It was shown that in Pakistan, the rapid expansion of population in rural areas can cause the shortage of existing energy resources and which motivates the Government and power companies to install new energy resources in these areas to fulfill the energy requirements and to improve the people's living standards living in these areas [13]. The roadmap of technologies in the energy sector that are used to handle the energy challenges in the country is published. According to the research, to install these roadmap technologies, rising the oil and gas prices and existing energy crises have not been discussed completely [19]. The identification of parameters affecting power system flexibility is also of the utmost importance [20].

Amjid et. al suggested that the national security policy must be reviewed to minimize the electricity bills as well as to use the biogas for producing electricity in the country [21]. Whereas another research work described that wind energy being a mature form of renewable energy can be a competitive power generation resource than the conventional thermal power at some locations in the country [22].

Sahir et. Al discussed that the interruption in the supplies of oil and gas due to the unstable situation in Afghanistan and Baluchistan is more likely to threaten the energy which can cause worse energy crises in the country [14]. There is a positive relationship between renewable energy resources and energy suppliers which is an important factor to overcome energy security issues. They also described that when there is a demand for energy, the country must not only rely on the existing energy resources but also exploit the other renewable energy resources to fulfill the electricity needs in the country especially in the remote areas of the country [23].

Renewable resources may be the long-term energy resources in Pakistan, but it cannot be serving as a substitute for conventional energy. It is discussed that the harnessing of energy cannot be perceived on the potential alone [14]. Whereas, biomass gas has been a necessary resource that is required to fully utilize the biogas technologies.

Advantages and disadvantages of hydrogen gas have not been discussed by the authors in their research although, they concluded that the hydrogen economy may help in reducing dependency on the oil imports, create a sustainable environment and economic competitiveness in the country. According to the authors, serious efforts are required to meet the challenges of the hydrogen economy in the country [24].

It has been emphasized that the development of wind power systems in Islamabad is not a feasible option, however, a wind power generation system installed on Margalla Hills at $80 \mathrm{~m}$ height may show promising results [25]. However, different power controlling mechanisms and network architectures give an insight into energy savings in future smart grid stations. According to the study, dynamic demand response management is a desirable feature of a smart grid system that can be integrated with individual household profiles using the Home Energy Management System. They also described that Balochistan province can only produce approximately 18 to $20 \mathrm{MW}$ per day after using 8 to 10 hours sunlight which may be the highest capacity of electricity production in the world [26].

Fifty-four percent of the rural population is living without electricity in Pakistan. This ratio is forcing them to live a substandard life of poverty and social discrimination. In rural areas, innovative, less costly tools need to be implemented to generate electricity from fossil fuels. For this purpose, different technologies can be used to convert these fossil fuels into electricity. Like other countries in the world, Pakistan has capabilities and expertise to handle the security issues of renewable energy resources. Several security issues exist to conventional energy resources such as management issues etc. To overcome the existing security issues of renewable energy resources through proper planning, a security environment must be created for the investors and also raise their confidence to invest in the energy sector. The most suitable solution to renewable energy security threats is the public-private partnership to improve the energy resources in the country.

Hence our study focuses on the conversion of fossil fuels into renewable energy and to overcome the renewable energy challenges in Pakistan. Whereas in rural areas there is a sheer need of study to overcome these challenges. This 
paper highlights and assesses these types of existing renewable energy issues.

\section{Methodology}

It is a difficult task to predict the most suitable renewable energy resource from the existing resources i.e. biomass gas, thermal power, solar system, wind energy and hydel energy resources for generating energy in a specific district of Pakistan. Since, the renewable energy depends upon the weather and climatic conditions, therefore, in our proposed framework, we have analyzed all expected security issues facing the country at this time as well as the optimal policy adopted by the Government of Pakistan to install the suitable renewable energy resource in any district of Pakistan based on information received from clouds about four districts.

Our proposed self-assessment agent can receive information patterns from four districts of Pakistan through clouds and then assessment of the possible security issues to install one of the suitable renewable energy systems from the existing renewable energy resources. In the self-assessment agent, the interoperability module is responsible to receive information patterns about the weather and climatic conditions about different districts and then proceeds the received information patterns to the memory for further action.

Where memory module is used to store the information, patterns received either from the external environment and generated within the system about the security threats and the proposed optimal renewable energy resource to the install according to geographical and environmental situations of the proposed district. A memory module is also responsible to process the new information patterns received from the external environment to the acquisition module.

The acquisition module is responsible to convert the new information patterns into the computer understand format and this converted information is processed to the data formatting module. This module is responsible to check the formatted data if the data is not in the proper format, it transmits the data to the data acquisition module with a request to re-transmit the data after proper formatting. The data formatting module then proceeds the properly formatted data to the data analyzation module.

Data analyzer is responsible to analyze the patterns of the information received from the external environment if these patterns are not in an understandable format, it transmits these patterns back to the data acquisition module. It is also responsible to analyze the received patterns whether these patterns are new and require any kind of learning and these patterns are already processed, if it analyzes that these patterns are required any kind of learning, it proceeds these patterns to learning module, otherwise, it proceeds these patterns to Government policies module. Where, the learning module is responsible to compare the newly received information patterns from the external environment with the already received and stored information patterns in the memory.
The Government policies module is responsible to analyze the possible security threats to install the proposed renewable energy resource in one of the four districts of Pakistan after analyzing its geographical and environmental situations. If there is anyone of the security issue such as circular debts, lack of local banks loan, the security situation of the country, the feudal system of a specific district like Sindh, Balochistan, lack of foreign investment, lack of appropriate technology and high cost of electricity, etc. then it decides another suitable renewable energy resource for that remote area. For this purpose, it proceeds the security threats information to the renewable energy resources module and checks the availability of an alternative renewable energy resource.

Fig.2: Rural Areas Interoperability Framework

\section{Results and Discussion}

For analyzing the performance of our proposed agent, we have adapted the Fuzzy Inference System (FIS), because FIS is the process of formulating the mapping from a given input to an output using Fuzzy Logic. The mapping provides the basis from which decisions can be made. In our proposed agent, FIS involves membership functions, Fuzzy Logic operators and IF-Then rules. We have used Mamdani type FIS for simulating our agent's behavior.

\subsection{Case - I}

Table 4: Fossil Fuel Prices, Govt. Subsidy Vs Power Generation

\begin{tabular}{|c|c|c|}
\hline \multicolumn{2}{|c|}{ Input Variables } & Output Variables \\
\hline $\begin{array}{c}\text { Fossil Fuel Prices } \\
\text { (FFP) }\end{array}$ & $\begin{array}{c}\text { Govt. Subsidy } \\
\text { (GS) }\end{array}$ & $\begin{array}{c}\text { Power } \\
\text { Generation (PG) }\end{array}$ \\
\hline
\end{tabular}




\begin{tabular}{|c|c|c|}
\hline No & No & No \\
\hline Less & No & High \\
\hline Average & No & High \\
\hline High & No & Less \\
\hline No & Yes & No \\
\hline Less & Yes & High \\
\hline Average & Yes & High \\
\hline High & Yes & Average \\
\hline
\end{tabular}

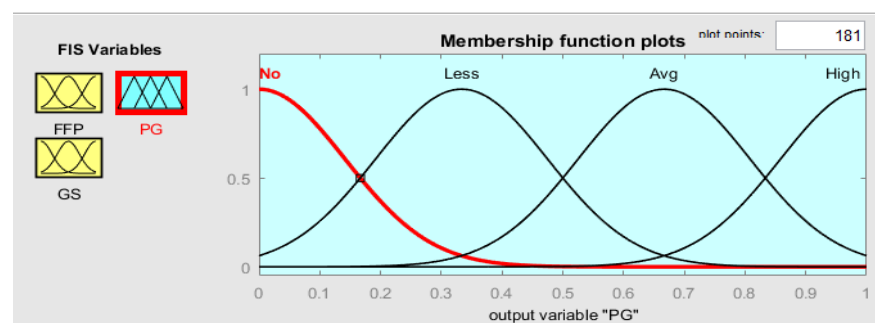

Fig: 3 (d)

Fig 3: (a) Input and Output Variables, (b) Fossil Fuel Prices Membership Functions, (c) Govt. Subsidy Membership Functions, (d) Power Generation Membership Functions

In Fig 3 (a), first of all, we have defined two input variables of our proposed agent i.e. Fossil Fuel Prices and Govt. The subsidy that is required to produce an output variable i.e. Power Generation. In Fig 3 (b), we have declared membership functions of each input and output variable. For Fossil Fuel Prices, we have defined four input membership functions such as No, Less, Avg, and High. Where we have represented these memberships equivalent to its numerical values i.e. $\mathrm{No}=0$, Less $=0.3$, Avg $=0.5$, and High-1. The range of each membership function is shown. In Fig 3 (c), we have declared two membership functions of our second input variable "Govt. subsidy (GS)" i.e. No, Yes, where $\mathrm{No}=0$ and $\mathrm{Yes}=1$. In Fig 3(d), we have defined four membership functions of our one output variable "Power Generation (PG)" i.e. No, Less, Average and High. The range of these membership functions is similar to Fossil Fuel Price membership functions.

We have defined 8 rules to analyze the impact of Fossil Fuel Prices and Government Subsidy to calculate the Power Generation from these two variables. We have shown the impact of these variables. Rules are as follows:

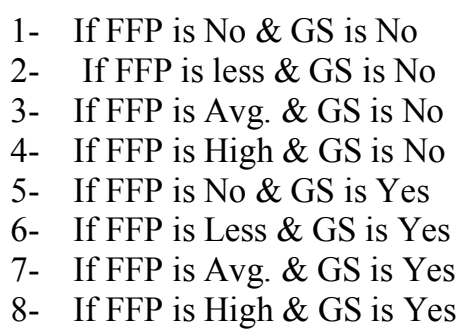

$P G$ is No $P G$ is High PG is High $P G$ is Less $P G$ is No PG is High PG is High $\mathrm{PG}$ is Avg.

In Fig 4 (a), we have shown that without setting the fossil fuel rates and government subsidy, it is not possible, we will be able to install a suitable renewable energy resource to produce electricity in any district of Pakistan. In Fig 4 (b), we have shown that if we have some money to purchase fossil fuels, then without the government support in the form of subsidy, we will be unable to produce electricity by installing any renewable energy resource.

Fig: 3 (c) 


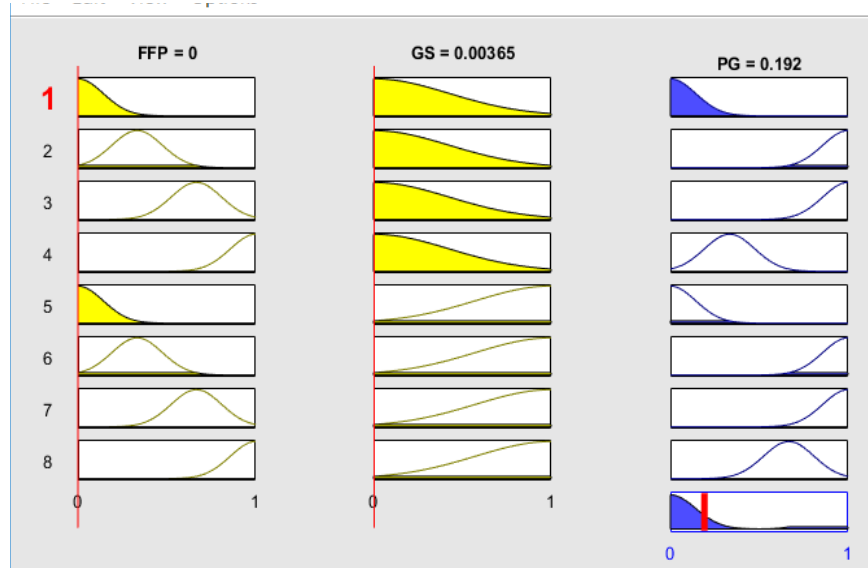

Fig 4: (a)

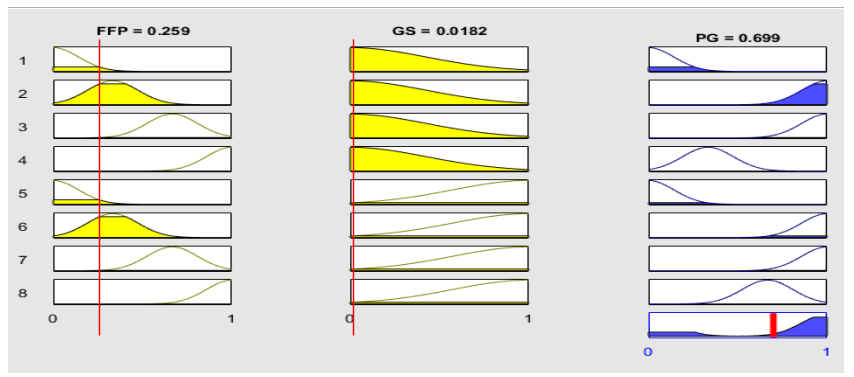

Fig 4: (b)

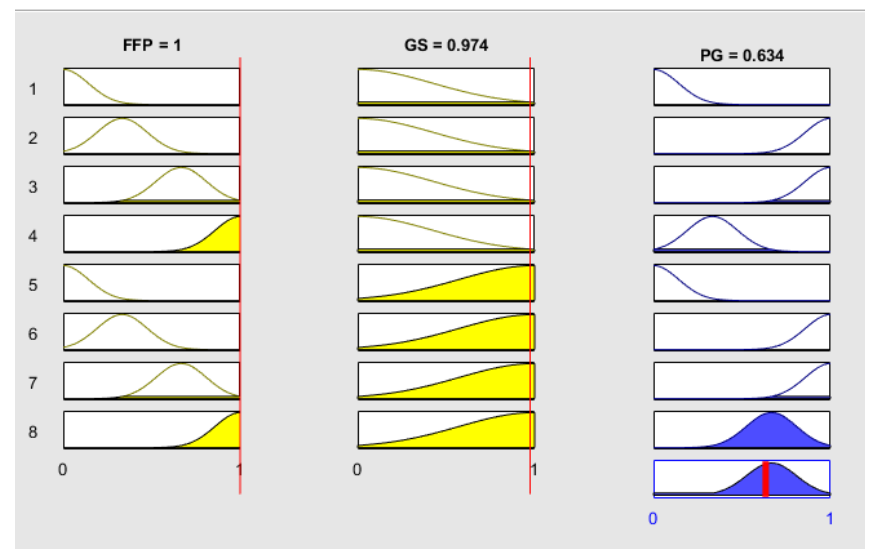

Fig 4: (c)

Fig 4: (a) No FFP, No GS \& No PG, (b) Less FFP, No GS, High PG, (c) High FFP, GS Yes and Avg, PG

In Fig. 4 (c), we have shown that when the Fossil Fuel prices are high as well as the Government allocated maximum subsidy for producing electricity, we can produce electricity only at an average level because of the high prices of fossil fuels. The impact of both inputs is shown in the third column i.e. average power production.

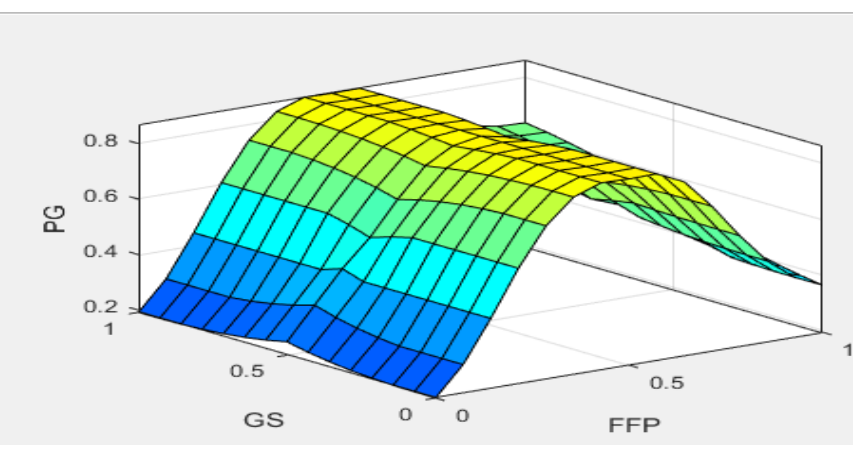

Fig 5: Impact of FFP and GS on PG

In Fig 5, we have shown the impact of Fossil Fuel Prices and Government Subsidy on the Power Generation in rural areas. As we have seen, when there is FFP means there is no fossil fuels are available in the country and no GS means Government is in crises and have no funds for the production of electricity, then there will be maximum hours of load shedding in the country and the same case when there are no fossil fuels are available although, Government issues some subsidy, we can't produce electricity without fossil fuels nor we are in a position to purchase fossil fuels with this subsidy amount. We are in the position to produce a high amount of electricity only we have fossil fuels at less price as well as the Government raise some subsidy. This impact of these is shown in the above-mentioned diagram.

\subsection{Case - II}

In the second scenario, we have quantities and price as input variables whereas Power Demand as the output variable.

Table 5: Quantity\& Price Vs Power Supply/Demand

\begin{tabular}{|c|c|c|}
\hline \multicolumn{2}{|c|}{ Input Variables } & Output Variable \\
\hline Quantities & Price & $\begin{array}{c}\text { Power } \\
\text { Demand/Supply }\end{array}$ \\
\hline No & No & No \\
\hline Less & No & Less \\
\hline Average & No & Less \\
\hline High & No & Less \\
\hline No & Less & Less \\
\hline Less & Less & Less \\
\hline Average & Less & Less \\
\hline High & Less & Less \\
\hline No & Average & Less \\
\hline Less & Average & Less \\
\hline Average & Average & Average \\
\hline High & Average & Less \\
\hline No & High & High \\
\hline Less & High & High \\
\hline Average & High & High \\
\hline High & High & Average \\
\hline \multicolumn{2}{|c}{} \\
\hline
\end{tabular}

The chosen values against these input/output variables have been provided in table 5 . The values are selected as:

Quantity: $\mathrm{No}=0$, Less $=0.3$, Average $=0.5$, High $=1$;

Prices: $\mathrm{No}=0$, Less $=0.3$, Average $=0.5$, High $=1$; 
Power Demand: $\mathrm{No}=0$, Less $=0.3$, Average $=0.5$, High $=1$.

Fig 6 (a) analyzes the impact of the availability of fossil fuels, and the rate of fossil fuels on the demand/supply of electricity in the country. For this purpose, we have defined two input variables i.e. the number of fossil fuels and the price of fossil fuels and one output variable i.e. power demand/supply (MW).

In Fig 6 (b), we have defined four-member functions for the number of fossil fuels available in Pakistan for generating electricity in rural areas by installing some renewable resources. It enables us to provide a deeper insight into the system.

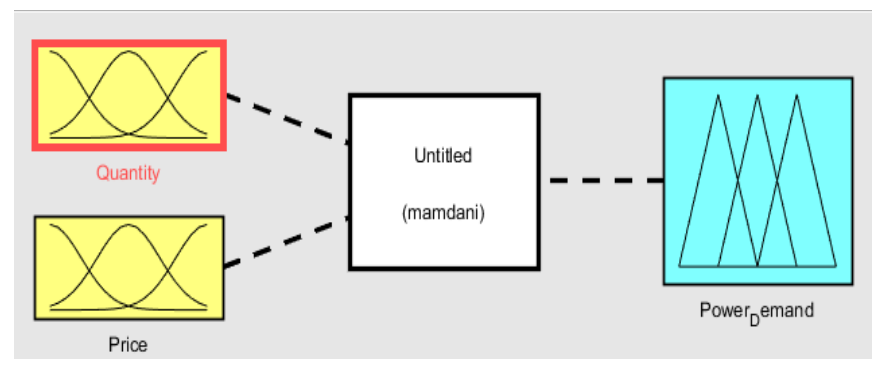

Fig 6: (a)

Fig 6: (b)

Fig 6: (c)

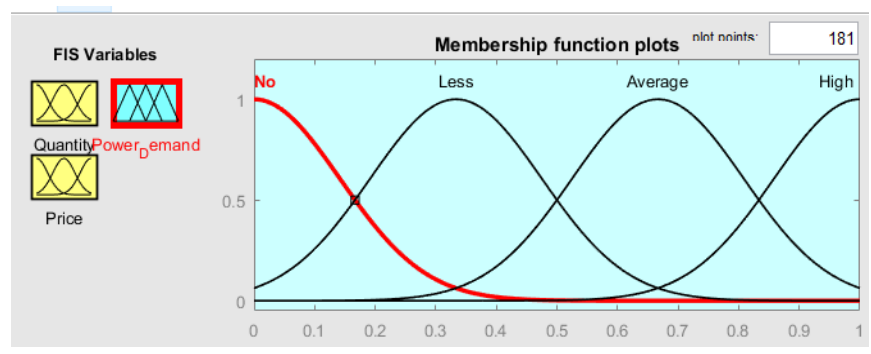

Fig 6: (d)

Fig 6: (a) Price and Quantity as Input Functions, (b) Quantity Membership Functions, (c) Price Membership Functions, (d) Power Demand Membership Functions.
. Fig 6 (c) shows the same membership functions for fossil fuel price input variables like the quantity of fossil fuel input variables to analyze it against demand/supply ratio for different scenarios to minimize the load shedding in rural areas. Fig. 6 (d) shows the same membership functions for Power Demand as the previous input variables.

For generating the impact of the number of fossil fuels and fossil fuel prices on the demand/supply of electricity in rural areas, we have defined sixteen rules. Every rule defines the relationship between input and out variables. Each rule is different and contains a unique relationship for simulation. It helps us to understand the different effects of quantities and prices on the Power demand and/or supply.

Fig 7: (a)

Fig 7: (b)

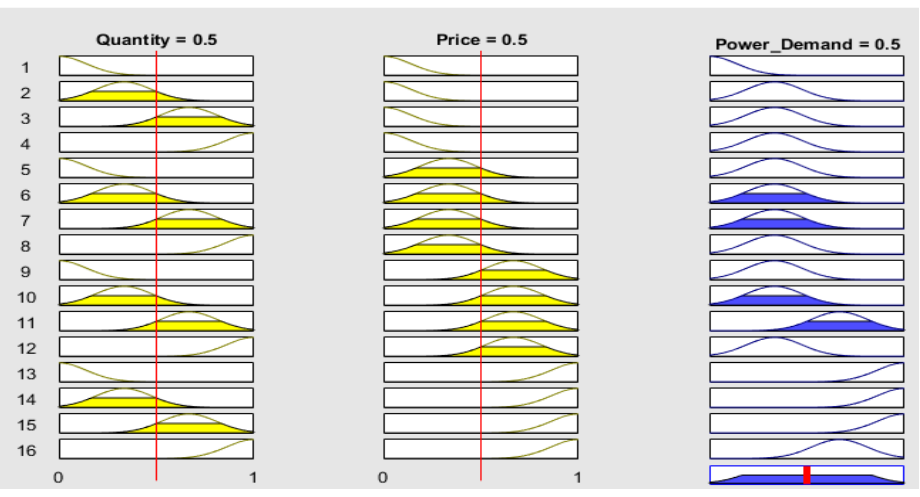

Fig 7: (c) 
Fig 7: (d)

Fig 7: (a) Less Quantity, No Price and Less Power Demand, (b) Less Quantity, High Price and High-Power Demand, (c) Average Quantity, Average Price and Average Power Demand, (d) High Quantity, High Price and Average Power Demand.

Fig 7 (a) shows that if we have some quantity of fossil fuels but we have nothing to purchase these fossil fuels, we are unable to install any renewable energy resource to convert these fossil fuels to generate electricity. Fig 7 (b) highlights if some quantity of fossil fuels and have a suitable amount to purchase these fossil fuels then we can generate maximum energy after converting these fossil fuels. Fig 7 (c) shows if we have an average quantity of fossil fuels and we have some amount to purchase these fuels then we are not in the position to produce too much electricity by these existing fossil fuels. Fig 7 (d) depicts that if we have a quantity of too many fuels and we have too much money to convert them, then we are in a good position to install a suitable renewable resource after analyzing the security threats to produce more electricity to fulfill the electricity demand in the rural areas.

Fig 8: Impact of Price and Quantity on Power Supply/Demand

Fig 8 , shows that at the initial stage when we have no fossil fuels, nor money issued by the government to purchase anything for generating electricity, we can't generate any electricity, but with time, as well as we have some fossil fuels and government has issued some money then we are in a position to install a suitable renewable energy resource after analyzing the security threats to produce some megawatt electricity, but after some time, if we have to much fossil fuels and the government allocated a suitable budget for energy generation purpose, then we are in a position to purpose more fossil fuels, by converting these fuels with the help of a renewable energy resource, we can produce a huge amount of electricity (MW).

\subsection{Case - III}

Table 6: Effect of Debts, Security Situation and Foreign Investment for Power Supply/Demand

\begin{tabular}{|c|c|}
\hline Input Variables & $\begin{array}{c}\text { Output } \\
\text { Variable }\end{array}$ \\
\hline
\end{tabular}

\begin{tabular}{|c|c|c|c|}
\hline Debts & $\begin{array}{c}\text { Security } \\
\text { Situation } \\
\end{array}$ & $\begin{array}{c}\text { Foreign } \\
\text { Investment }\end{array}$ & $\begin{array}{l}\text { Quantity } \\
\text { (KW/h) }\end{array}$ \\
\hline No & No & No & More \\
\hline Less & No & No & More \\
\hline Avg & No & No & Less \\
\hline More & No & No & No \\
\hline No & Less & No & More \\
\hline Less & Less & No & More \\
\hline Avg & Less & No & Less \\
\hline More & Less & No & No \\
\hline No & Avg & No & Less \\
\hline Less & Avg & No & Less \\
\hline Avg & Avg & No & No \\
\hline More & Avg & No & No \\
\hline No & More & No & No \\
\hline Less & More & No & No \\
\hline Avg & More & No & No \\
\hline More & More & No & No \\
\hline No & No & Less & Avg \\
\hline Less & No & Less & Avg \\
\hline Avg & No & Less & Less \\
\hline More & No & Less & Less \\
\hline No & Less & Less & Avg \\
\hline Less & Less & Less & Avg \\
\hline Avg & Less & Less & No \\
\hline More & Less & Less & No \\
\hline No & Avg & Less & Less \\
\hline Less & Avg & Less & Less \\
\hline Avg & Avg & Less & No \\
\hline More & Avg & Less & No \\
\hline No & More & Less & No \\
\hline Less & More & Less & No \\
\hline Avg & More & Less & No \\
\hline More & More & Less & No \\
\hline No & No & Avg & More \\
\hline Less & No & Avg & More \\
\hline Avg & No & Avg & Avg \\
\hline More & No & Avg & Less \\
\hline No & Less & Avg & More \\
\hline Less & Less & Avg & Avg \\
\hline Avg & Less & Avg & Less \\
\hline More & Less & Avg & Less \\
\hline No & Avg & Avg & Avg \\
\hline Less & Avg & Avg & Less \\
\hline Avg & Avg & Avg & No \\
\hline More & Avg & Avg & No \\
\hline No & More & Avg & Less \\
\hline Less & More & Avg & Less \\
\hline Avg & More & Avg & No \\
\hline More & More & Avg & No \\
\hline No & No & More & More \\
\hline Less & No & More & More \\
\hline Avg & No & More & Avg \\
\hline More & No & More & Less \\
\hline No & Less & More & More \\
\hline Less & Less & More & More \\
\hline Avg & Less & More & Avg \\
\hline More & Less & More & Less \\
\hline
\end{tabular}




\begin{tabular}{|c|c|c|c|}
\hline No & Avg & More & Avg \\
\hline Less & Avg & More & Less \\
\hline Avg & Avg & More & No \\
\hline More & Avg & More & No \\
\hline No & More & More & No \\
\hline Less & More & More & No \\
\hline Avg & More & More & No \\
\hline More & More & More & No \\
\hline
\end{tabular}

To analyze, how much we can retain electricity (MW) to fulfill the electricity demand in the peak season, it depends up the three input factors i.e. debts that Government has to pay to its internal banks as well as foreign debts, foreign investment in the power sector and security risks like terrorism, bomb blast, opposition parties rely on against Government policies, our feudal system, etc. as shown in Fig. 9 (a). whereas for the simulation purpose, values for variable functions given in table 6 are set as follows:

Debt: $\mathrm{No}=0, \mathrm{Less}=0.3, \mathrm{Avg}=0.5$, More $=1$

Security Situation: $\mathrm{No}=0, \mathrm{Less}=0.3, \mathrm{Avg}=0.5$, More $=1$

Foreign Investment: $\mathrm{No}=0$, Less $=0.3$, More $=1$

Quantity: $\mathrm{No}=0$, Less $=0.3, \mathrm{Avg}=0.5$, More $=1$

Fig 9: (a)

Fig 9: (b)
Fig 9: (c)

Fig 9: (d)

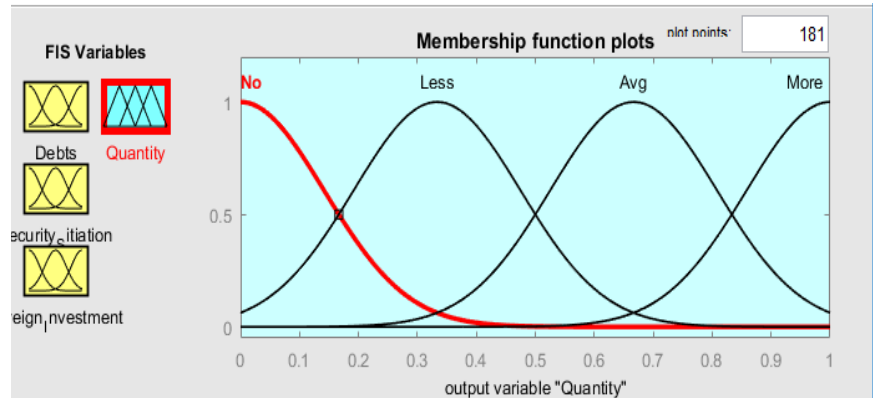

Fig 9: (e)

Fig 9: (a) Input Variables for Power Quantity, (b) Debts Membership Functions, (c) Security Situation Membership Functions, (d) Foreign Investment Membership Functions, (e) Quantity Membership Functions.

In Fig 9 (b), we have shown four membership functions of Debts variable i.e. there is "No" debts on Pakistan to pay to its internal banks as well as to pay foreign debts, "Less", "Avg" and "More" debt ratio has to pay. In Fig 9 (c), we have taken three membership functions of "Security Situation" variable i.e. "No", "Less", "Avg" and "High", which shows that if there is no security risk in the country, then Pakistan will be in the position of produce and retain more electricity and there will be no shortfall in the country even in the peak summer season. If there are a few security risks in the country and which can maintain easily by deploying more forces and rescue police in the unrest areas, these situations can't much affect the production of electricity in the country and so on. In Fig. 9 (d), we have declared four membership functions i.e. "No", "Less", "Avg" and "High" which means to produce and retain electricity to minimize the load shedding. It means that if there is No or Less foreign investment in the country although, the remaining factors not much effect, there is no or less 
electricity can be produced and if there is a huge investment in the country, then Pakistan will be in the position to produce more electricity to fulfill its electricity requirements as well as sale to other countries. In (e) we have defined four membership functions to our defined output variable "Quantity" i.e. "No", "Less", "Avg" and "High". These membership functions can be changed based on the defined membership functions of each variable. The impact of the input variables on the output variable is defined in the later on figures.

We have 64 possible rules, as shown in fig. 10, to produce and retain electricity quantity (MW) to fulfill its electricity demand as well to sale other countries based on the combination of membership functions of three input variables i.e. "debts", "security situation" and "foreign investment".

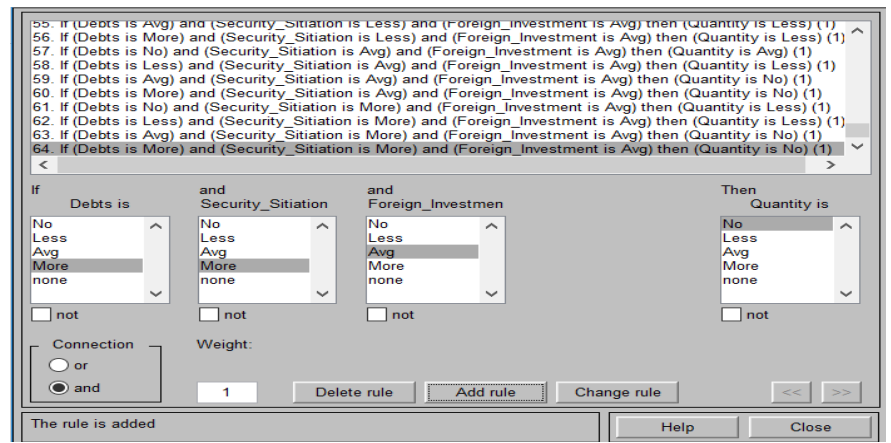

Fig 10: Power Quantity Rules Editors

In Fig 11 (a), we have shown the impact of three input variables i.e. Debts, security Situation and Foreign Investment to one output variable i.e. Quantity (MW). When there is no debt on the country, no security threat in the country and there is no foreign investment, we can produce electricity to fulfill some of our electricity demands because by the existing budget we have to achieve other goals.

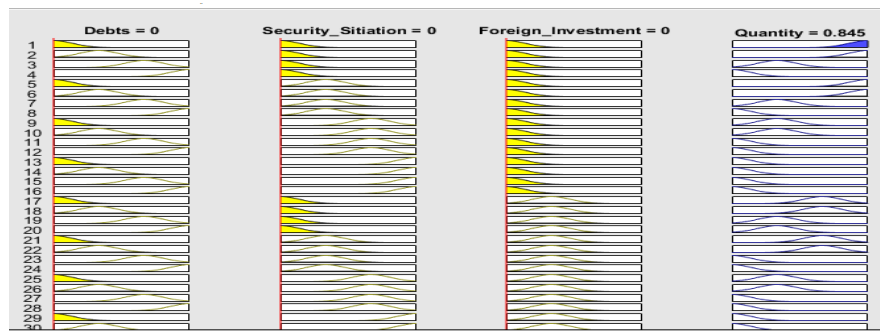

Fig 11: (a)

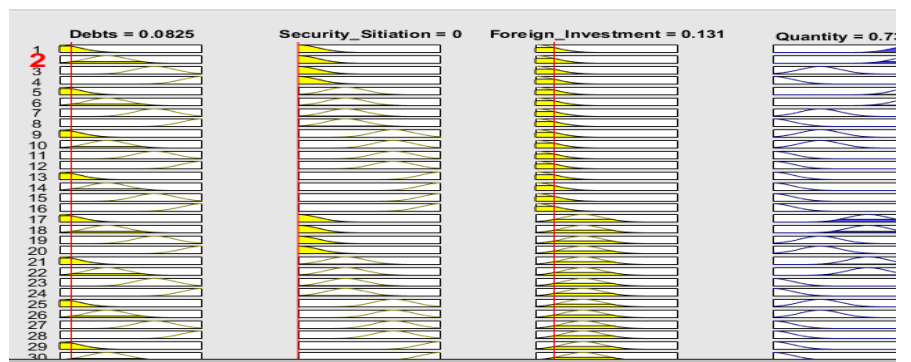

Fig 11: (b)
Fig 11: (c)

Fig 11: (d)

Fig 11: (a) No Debts, No-Risk, No Foreign Investment \& More Power Generation, (b) Less Debts, No Security Issues, less Foreign Investments, Average Power Generation, (c) No Debts, Average Security Situation, No Foreign Investments, Less Power Generation, (d) More Debts, Security issues high, More Foreign Investment, No Power Generation

In Fig 11 (b), we have shown that if there is some foreign investment in the country, although, there are little bit debts on the country and there is no security threat, Pakistan will be in the position to produce some electricity to fulfill its electricity demands at some extent. Fig 11 (c) shows that if there are no debts have to pay to its internal banks as well as to other countries and there is some foreign investment in the country, but there are some security risks in the country, then the country will not be in the position to produce more electricity due to these security threats to the power sector. Fig 11 (d) illustrates that although there is huge foreign investment in the country there are huge foreign debts have to pay in the financial year and security threat are very high, there is no power production due to this high unrest in the country.

Fig 12 (a) shows the impact of debts to have pay to internal banks as well as to foreign counties and security situation in the country on the production of electricity in the country. The comparison of different membership functions of these two variables on the electricity production in quantity (MW) is shown in the diagram. 


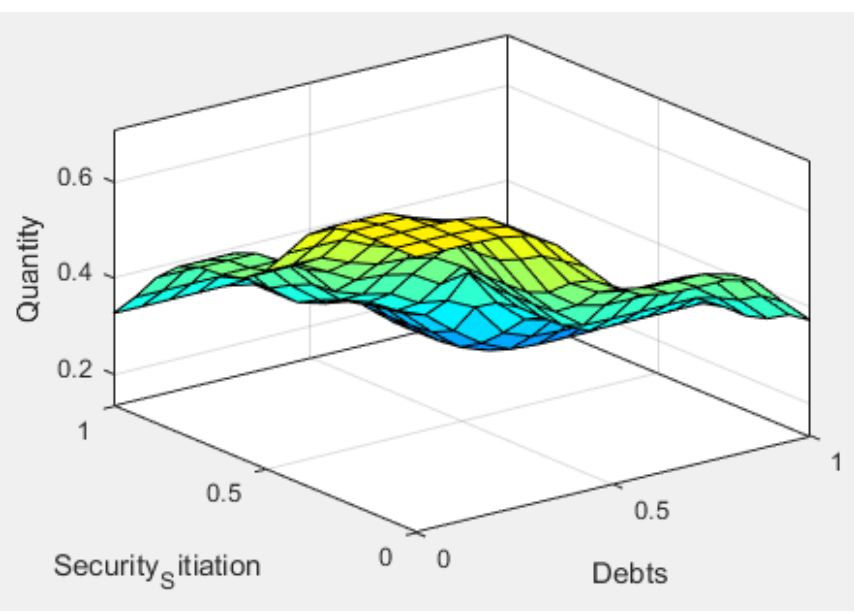

Fig 12: (a)

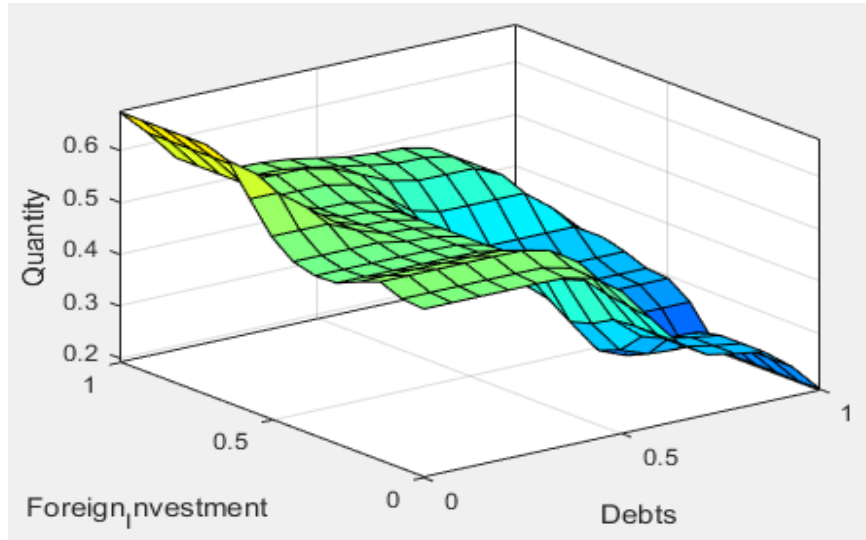

Fig 12: (b)

Fig 12: (a) Impact of Debts and Security Situation on Power Generation Quantity, (b) Impact of Debts and Foreign Investment on Power Generation Quantity.

The central part of the diagram shows if there is no debt to pay on the country, the security situation is suitable to produce more electricity and there is huge foreign in the country, then the country will be in the position to install more renewable resources in the rural areas to fulfill its electricity requirement and avoid to less load on the existing power stations.

Fig 12 (b) shows that if there is huge foreign investment in the country and debt ratio is no or very less, then there are more chances to install more renewable power stations in the rural areas. If there is no less investment and no debts to pay, there is an average level of installment of renewable resources. If average investment and average debts then are the installment of renewable resources in less areas and if more investment but less debts to pay then the installment of renewable resources will be at very large areas even in faraway areas where installment of renewable resources is impossible.

\section{Conclusions}

The government of Pakistan is struggling for the last 10 years to overcome its energy crises in the form of load shedding especially in rural areas that are reached upto16 to 18 hours in the peak summer season. Pakistan is facing an exceptional energy threat, which leads to propose an effective long-term energy solution. Renewable energy resources such as wind, solar, biomass, biogas, thermal are abundant in Pakistan and show significant technical potential to meet energy needs. In general, evaluating renewable energy security issues is a complex task but it is necessary to define multi-dimensional indicators and their objectives. However, the development of a renewable energy power project in the rural area is stalled by several economic, technical, institutional and informational barriers. The government policies make important steps towards energy but an autonomous system provides an authenticated and reliable solution as an alternative conventional energy resource for remote areas of Pakistan.

In table 4 and Fig 3-5 our proposed agent has analyzed the relationship between the rate of fossil fuels and government subsidy to produce the power generation (MW). In table 5 and Fig 6-8, we have shown that our proposed agent compares the relationship between the number of available fossil fuels, price of fossil fuels and power generation, which shows that if the government gives some subsidy to purchase the fossil fuels then we can be in the position to produce more electricity by installing a suitable renewable resource after analyzing the security situation in the area. In table 6 and Fig 9-12, our proposed agent is comparing the relationship between debts that have to pay by the government to its internal banks as well as other countries, security situations in the country, foreign investment and power generation. The agent will review, if there are no debts to pay, no foreign investment in the country, country security situation is not good, then they're in no chance to install a suitable renewable resource to produce electricity but if the security situation becomes better and if there is some foreign investment in the country and if the country has not paid any foreign debts, then we are in the position to install a suitable energy resource to produce electricity to minimize the load shedding crisis in the country especially in the rural areas.

\section{References}

[1] H. A. Pasha and W. Saleem, "The Impact and Cost of Power Load Shedding to Domestic Consumers," The Pakistan Development Review, vol. 52, no. 4, pp. 355372, 2013.

[2] D. I. Khan, "Impact of energy crisis on economic growth of Pakistan," pp. 33-42, 2015.

[3] S. A. U. Rehman, Y. Cai, N. H. Mirjat, G. D. Walasai, I. A. Shah, and S. Ali, "The Future of Sustainable Energy Production in Pakistan: A System Dynamics-Based Approach for Estimating Hubbert Peaks," vol. 10, no. 11, p. 1858, 2017.

[4] A. Farooq and K. Tayyab, "Implementation of a low cost efficient microcellular renewable energy system," in 2014 International Conference on Energy Systems and Policies (ICESP), 2014, pp. 1-5. 
[5] D. H. Romero, D. Icaza, and J. González, "Technical - Economic Study for the Implementation of Solar Energy in the Presence of Biomass and Micro Hydraulic Generation, for Sectors that do not Have Electricity Supply in the Province of Bolívar-Ecuador," in 2019 7th International Conference on Smart Grid (icSmartGrid), 2019, pp. 149-154.

[6] E. M. Malatji, "The use of Dynamic Tariff by The Utilities to Counter act The Influence of Renewable Energy Sources," in 2019 7th International Conference on Smart Grid (icSmartGrid), 2019, pp. 103-107.

[7] D. Motyka, M. Kajanová, and P. Braciník, "The Impact of Embedded Generation on Distribution Grid Operation," in 2018 7th International Conference on Renewable Energy Research and Applications (ICRERA), 2018, pp. 360-364.

[8] Mehdy Khayamy, Adel Nasiri, and M. H. Balali, "Analytical Study Based Optimal Placement of Energy Storage Devices in Power Systems to Support Voltage and Angle Stability," International Journal of Smart Grid - ijSmartGrid, vol. 3, no. 4, pp. 208-215, 22.10.2019 2019.

[9] H. Aras, Ş. Erdoğmuş, and E. Koç, "Multi-criteria selection for a wind observation station location using analytic hierarchy process," Renewable Energy, vol. 29, no. 8, pp. 1383-1392, 2004/07/01/ 2004.

[10] H. B. Khalil and N. Abas, "Smart grids: An approach to integrate the renewable energies and efficiently manage the energy system of Pakistan," in Fifth International Conference on Computing, Communications and Networking Technologies (ICCCNT), 2014, pp. 1-7.

[11] M. Kamran, M. R. Fazal, M. Mudassar, M. Adnan, I. Abid, F. J. S. Randhawa, H. Shams, "Solar photovoltaic grid parity: a review of issues, challenges, and status of different PV markets," International Journal of Renewable Energy Research, vol. 9, no. 1, pp. 244-260, 2019.

[12] M. M. Rafique and G. Ahmad, "Targeting sustainable development in Pakistan through the planning of integrated energy resources for electricity generation," The Electricity Journal, vol. 31, no. 7, pp. 14-19, 2018/08/01/ 2018.

[13] M. A. Ghaffar, "The energy supply situation in the rural sector of Pakistan and the potential of renewable energy technologies," Renewable Energy, vol. 6, no. 8, pp. 941-976, 1995/11/01/ 1995.

[14] M. H. Sahir and A. H. Qureshi, "Specific concerns of Pakistan in the context of energy security issues and geopolitics of the region," Energy Policy, vol. 35, no. 4, pp. 2031-2037, 2007/04/01/ 2007.

[15] A. Mahmood, N. Javaid, A. Zafar, R. Ali Riaz, S. Ahmed, and S. Razzaq, "Pakistan's overall energy potential assessment, comparison of LNG, TAPI and IPI. gas projects," Renewable and Sustainable Energy Reviews, vol. 31, pp. 182-193, 2014/03/01/ 2014.

[16] M. Kamran, M. R. Fazal, and M. Mudassar, "Towards empowerment of the renewable energy sector in Pakistan for sustainable energy evolution: SWOT analysis," Renewable Energy, vol. 146, pp. 543-558, 2020/02/01/ 2020.

[17] A. Raheem et al., "Renewable energy deployment to combat energy crisis in Pakistan," Energy, Sustainability and Society, vol. 6, no. 1, p. 16, 2016/06/22 2016.

[18] J. Solis, T. Oka, J. Ericsson, and M. Nilsson, "Forecasting of Electric Energy Consumption for Housing Cooperative with a Grid Connected PV System," in 2019 7th International Conference on Smart Grid (icSmartGrid), 2019, pp. 118-125.

[19] M. Asif, "Sustainable energy options for Pakistan," Renewable and Sustainable Energy Reviews, vol. 13, no. 4, pp. 903-909, 2009/05/01/ 2009.

[20] P. Mazidi, G. N. Baltas, M. Eliassi, and P. Rodríguez, "A Model for Flexibility Analysis of RESS with Electric Energy Storage and Reserve," in 2018 7th International Conference on Renewable Energy Research and Applications (ICRERA), 2018, pp. 1004-1009.

[21] S. S. Amjid, M. Q. Bilal, M. S. Nazir, and A. Hussain, "Biogas, renewable energy resource for Pakistan," Renewable and Sustainable Energy Reviews, vol. 15, no. 6, pp. 2833-2837, 2011/08/01/ 2011.

[22] A. W. Bhutto, A. A. Bazmi, and G. Zahedi, "Greener energy: Issues and challenges for PakistanBiomass energy prospective," Renewable and Sustainable Energy Reviews, vol. 15, no. 6, pp. 3207-3219, 2011/08/01/ 2011.

[23] T. Chien and J.-L. Hu, "Renewable energy: An efficient mechanism to improve GDP," Energy Policy, vol. 36, no. 8, pp. 3045-3052, 2008/08/01/ 2008.

[24] U. K. Mirza, N. Ahmad, K. Harijan, and T. Majeed, "A vision for hydrogen economy in Pakistan," Renewable and Sustainable Energy Reviews, vol. 13, no. 5, pp. 1111-1115, 2009/06/01/ 2009.

[25] F. A. Shifa and M. F. U. Butt, "A feasibility study for deployment of wind energy-based power production solution in Islamabad, Pakistan," in 2012 International Conference on Emerging Technologies, 2012, pp. 1-6. 
INTERNATIONAL JOURNAL Of SMART GRID

S. Nasem et al., Vol.4, No.2, June, 2020

[26] N. Khan, I. A. Mirza, and M. Khalil. (2014, 2

Available:

http://www.aedb.org/ March). Renewable energy in Pakistan: status and trends. 